\title{
Risk factors for atherosclerosis and the degeneration of pericardial valves after aortic valve replacement
}

\author{
Georg Nollert, MD \\ Jessica Miksch, MD \\ Eckart Kreuzer, MD \\ Bruno Reichart, MD
}

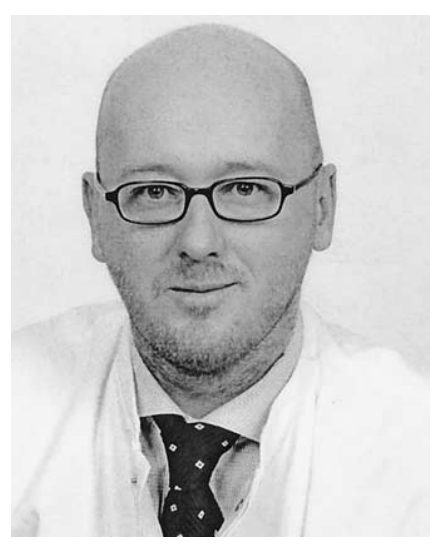

Dr Nollert

See related articles on pages 939 and 969.
From the Department of Cardiac Surgery,
University of Munich, Munich, Germany.
Received for publication July 26, 2002; re-
visions requested Sept 24, 2002; revisions

Background: Recent studies have demonstrated the influence of atherosclerotic risk factors on the progression of aortic stenosis. We hypothesized that risk factors for atherosclerosis might also be involved in the degeneration of pericardial heart valves and might lead to reoperation as a result of structural valve failure, especially in younger patients with high degeneration rates.

Methods: In 1984 and 1985, 161 patients (74\% male; mean age, $54.4 \pm 1.0$ years; age range, $17-76$ years; median age, 56.5 years $)$ survived isolated aortic $(\mathrm{n}=137)$ or combined aortic and mitral $(\mathrm{n}=25)$ valve replacement with a Hancock extracorporeal pericardial valve. Of these patients, $90(56 \%)$ had reoperations as a result of tissue failure of the aortic valve $5.6 \pm 0.25$ years postoperatively.

Results: The patient group was split in half at the median age. In patients aged 57 years or younger, diabetes mellitus, female sex, cigarette smoking, and high cholesterol and triglyceride levels were associated with accelerated valve failure. In a multivariate model sex (female, $P=.001)$, smoking $(P=.001$ ), diabetes mellitus $(P=.020)$, and cholesterol levels $(P=.011)$ are risk factors for reoperation. Patients without risk factors had reoperation after a mean of $9.25 \pm 0.88$ years compared with $4.05 \pm 0.43$ years $(P=.0002)$ in patients with 2 or 3 risk factors.

Conclusions: Risk factors of atherosclerosis might play a substantial role in the degeneration of aortic bioprosthetic valves. Lowering of serum lipid levels, smoking cessation, therapy for diabetes, and careful patient selection could be new strategies to postpone degeneration. Younger patients could then possibly benefit from the advantages of bioprostheses.

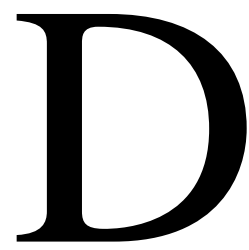

egeneration of biologic heart valve prostheses is believed to depend on the mechanical properties of the valve and on immunologic and calcification processes. Degeneration of the native valve also involves mechanical stress and calcific and immunologic mechanisms. Recent studies demonstrated that risk factors of atherosclerosis accelerate the progression of aortic stenosis. ${ }^{1}$ We hypothesized that these risk factors, including sex, cigarette smoking, diabetes mellitus, and increased levels of cholesterol and triglycerides, might increase the degeneration of biologic heart valves in patients after aortic valve replacement. The hypothesis was tested by retrospectively investigating a group of patients who received the Hancock pericardial valve in the mid-1980s at our institution. This patient group was chosen because the valve had a high incidence of primary tissue failure with consecutive reoperations, and lipid-lowering drugs were not in clinical use.

\section{Methods}

In 1984 and 1985, 161 patients ( $74 \%$ male; mean age, $54.4 \pm 11.0$ years; age range, 17-76 years; median age, 56.5 years $)$ survived isolated aortic $(n=137)$ or combined aortic and
Address for reprints: Georg Nollert, MD, Grosshadern, Marchioninistr. 15, 81366

J Thorac Cardiovasc Surg 2003;126:965-8

Copyright (C) 2003 by The American Association for Thoracic Surgery

0022-5223/2003\$30.00+0

doi:10.1016/S0022-5223(02)73619-2 online.de). 
TABLE 1. Preoperative patient characteristics

\begin{tabular}{|c|c|c|c|c|c|c|c|}
\hline & $\begin{array}{c}\text { All } \\
\text { patients }\end{array}$ & & Young patients ( $\leq 57 \mathrm{y}$ ) & & & Elderly patients (>57 y) & \\
\hline & $P$ value & $\mathbf{n}$ & $\begin{array}{l}\text { Longevity of the valve, mean and } \\
95 \% \text { confidence interval }(\mathrm{y})\end{array}$ & $\begin{array}{c}P \\
\text { value }\end{array}$ & $\mathbf{n}$ & $\begin{array}{l}\text { Longevity of the value, mean } \\
\text { and } 95 \% \text { confidence } \\
\text { interval }(y)\end{array}$ & $\begin{array}{c}P \\
\text { value }\end{array}$ \\
\hline Indication for AVR & & & & & & & \\
\hline $\begin{array}{l}A S \\
A R\end{array}$ & .348 & $\begin{array}{l}44 \\
42\end{array}$ & $\begin{array}{l}7.44(5.96-8.91) \\
7.45(6.11-8.80)\end{array}$ & .722 & $\begin{array}{l}54 \\
21\end{array}$ & $\begin{array}{l}6.82(5.33-8.32) \\
8.24(6.33-10.15)\end{array}$ & .181 \\
\hline Sex & & & & & & & \\
\hline $\begin{array}{l}\text { Female } \\
\text { Male }\end{array}$ & .208 & $\begin{array}{l}13 \\
73\end{array}$ & $\begin{array}{l}5.03(3.93-6.13) \\
8.07(6.89-9.26)\end{array}$ & .0047 & $\begin{array}{l}36 \\
39\end{array}$ & $\begin{array}{l}7.46(5.43-9.49) \\
7.01(5.81-8.20)\end{array}$ & .923 \\
\hline Cigarette smoking & & & & & & & \\
\hline $\begin{array}{l}\text { Never } \\
\text { History } \\
\text { Active }\end{array}$ & .078 & $\begin{array}{l}47 \\
26 \\
13\end{array}$ & $\begin{array}{l}8.23(6.85-9.61) \\
6.34(5.22-7.47) \\
4.64(3.98-5.31)\end{array}$ & .0119 & $\begin{array}{r}49 \\
17 \\
9\end{array}$ & $\begin{array}{r}7.5(5.94-9.06) \\
6.35(4.68-8.02) \\
6.31(4.31-8.48)\end{array}$ & .707 \\
\hline Diabetes mellitus & & & & & & & \\
\hline $\begin{array}{l}\text { IDDM or NIDDM } \\
\text { No }\end{array}$ & .574 & $\begin{array}{r}4 \\
82\end{array}$ & $\begin{array}{l}3.95(3.23-4.67) \\
7.65(6.61-8.69)\end{array}$ & $<.0001$ & $\begin{array}{l}10 \\
65\end{array}$ & $\begin{array}{l}6.71(5.81-7.62) \\
7.08(5.75-8.42)\end{array}$ & .264 \\
\hline Cholesterol [mg/dL] & & & & & & & \\
\hline $\begin{array}{l}\leq 240 \mathrm{mg} / \mathrm{dL} \\
>240 \mathrm{mg} / \mathrm{dL}\end{array}$ & .601 & $\begin{array}{l}54 \\
32\end{array}$ & $\begin{array}{l}8.42(7.06-9.79) \\
6.21(4.30-8.12)\end{array}$ & .0207 & $\begin{array}{l}42 \\
33\end{array}$ & $\begin{array}{l}6.32(5.36-7.28) \\
8.44(6.39-10.49)\end{array}$ & .141 \\
\hline Triglyceride [mg/dL] & & & & & & & \\
\hline $\begin{array}{l}\leq 123 \mathrm{mg} / \mathrm{dL} \\
>123 \mathrm{mg} / \mathrm{dL}\end{array}$ & .1384 & $\begin{array}{l}43 \\
43\end{array}$ & $\begin{array}{l}8.66(7.03-10.30) \\
6.29(5.14-7.45)\end{array}$ & .0448 & $\begin{array}{l}38 \\
37\end{array}$ & $\begin{array}{l}7.12(5.85-8.39) \\
7.59(5.55-9.62)\end{array}$ & .9243 \\
\hline $\begin{array}{c}\text { Body mass index } \\
<25 \mathrm{~kg} / \mathrm{BSA}^{2} \\
>25 \mathrm{~kg} / \mathrm{BSA}^{2}\end{array}$ & .574 & 46 & $8.36(6.77-9.95)$ & .109 & 51 & $6.88(5.29-8.48)$ & .313 \\
\hline
\end{tabular}

Parameters showing significant influence on valve longevity are printed in italics $(P<.05)$ or bold $(P<.01)$.

$A V R$, Aortic valve replacement; $A S$, aortic stenosis; $A R$, aortic regurgitation; $B S A$, body surface area; IDDM, insulin-dependent diabetes mellitus; NIDDM, noninsulin-dependent diabetes mellitus.

mitral $(n=25)$ valve replacement with a Hancock extracorporeal pericardial valve. Patients with significant concomitant coronary artery disease were excluded from our study. Of these 161 patients, $90(56 \%)$ had reoperations as a result of tissue failure of the aortic valve $5.6 \pm 0.25$ years postoperatively. Because degeneration of biologic heart valves, the influence of lipids on atherosclerosis, and lipid serum levels are known to be age dependent, ${ }^{1,2}$ the patient group was split in half at the median age. Preoperative patient characteristics of young ( $\leq 57$ years) and elderly ( $>57$ years) patients are summarized in Table 1. Patients were categorized as those with normal and high cholesterol levels by using the commonly used cutoff point at $240 \mathrm{mg} / \mathrm{dL}$ to analyze the influence of serum lipids on valve failure. For triglyceride levels, the median value of $123 \mathrm{mg} / \mathrm{dL}$ was used as the cutoff point.

Preoperative hypertension and renal failure are not presented because preoperative hypertension obviously depends on aortic valve disease, and renal failure was considered a contraindication.

Values are expressed as means and SEM. The Student $t$ test was used to compare absolute quantitative values. Reoperation, longevity of valves, and survival rates were calculated by using the actuarial method and tested with the log-rank test. Every univariate parameter reaching or approaching significance $(P<.1)$ was then tested in a Cox multivariate model.

\section{Results}

\section{Reoperation as a Result of Tissue Failure}

Data on reoperation as a result of tissue failure are shown in Table 1 and Figure 1 . In the entire patient population, none of the investigated risk factors significantly influenced the reoperation rate caused by tissue failure. Only smoking tended to influence valve longevity negatively $(P=.078)$.

Young patients ( $\leq 57$ years). In patients aged 57 years or younger, diabetes mellitus, female sex, cigarette smoking, and high cholesterol and triglyceride levels were associated with accelerated valve failure. In a multivariate model sex (female, $P=.001)$, smoking $(P=.001)$, diabetes mellitus $(P=.020)$, and high cholesterol levels $(>240$ $\mathrm{mg} / \mathrm{dL}, P=.011)$ are risk factors for reoperation. Patients without risk factors had reoperation after a mean of $9.25 \pm$ 0.88 years compared with $4.05 \pm 0.43$ years $(P<.0001)$ in patients with 2 or 3 risk factors and $6.99 \pm 0.66$ years in patients 65 years or older $(P=.124)$. In female patients diabetes mellitus ( $18 \%$ vs $3 \%, P=.031)$ was more frequent, and cholesterol (252 vs $220 \mathrm{mg} / \mathrm{dL}, P=.05$ ) and triglyceride levels (176 vs $137 \mathrm{mg} / \mathrm{dL}, P=.105$ ) were higher than in male patients. 

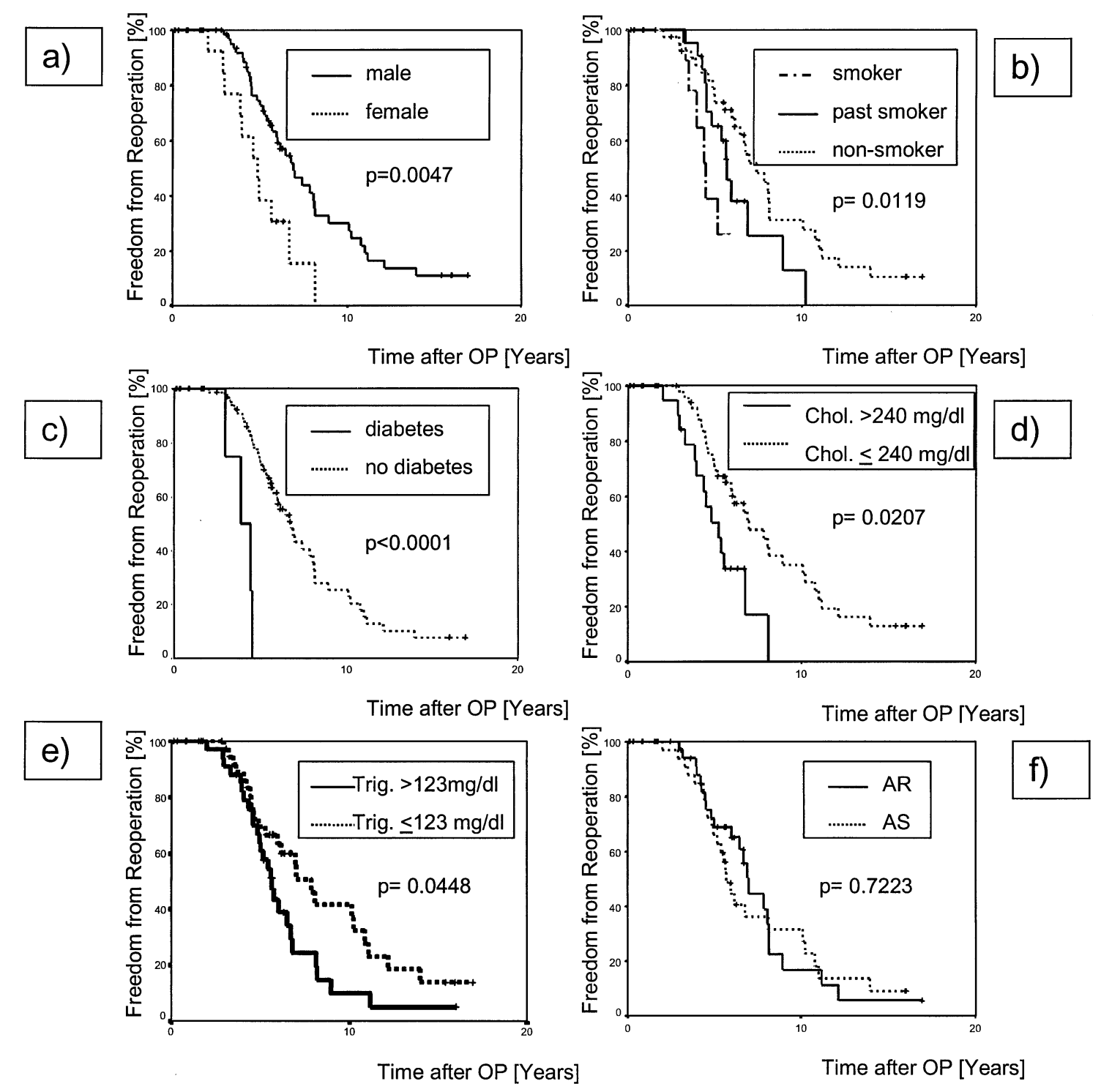

Figure 1. Reoperation rate according to preoperative characteristics in younger patients (<57 years). Degeneration of the Hancock pericardial aortic bioprosthesis leading to reoperation is substantially influenced by sex (a), smoking habits (b), diabetes mellitus (c), cholesterol levels (d), and triglyceride levels (e). Indication for surgical intervention had no effect on reoperation (f). OP, Operation; Chol, cholesterol; Trig, triglyceride; $A R$, aortic regurgitation; $\boldsymbol{A S}$, aortic stenosis.

Elderly patients ( $>57$ years). In elderly patients $(>57$ years) valve longevity was not significantly influenced by any of the investigated parameters.

\section{Survival}

None of the investigated risk factors had a significant effect on survival after aortic valve replacement, and only smoking tended to decrease life expectancy in younger patients $(P=.052)$.

\section{Discussion}

Despite the excellent hemodynamic properties of bioprostheses, aortic valve replacement with bioprostheses is generally not advocated in patients younger than 65 years $^{3}$ because accelerated degeneration increases the risk of reoperation in younger patients. In our study we demonstrate associations between risk factors for atherosclerosis and degeneration of aortic pericardial valves in younger but not in elderly patients, suggesting additional mechanisms of degeneration in the young age group. 
Premature failure of the second-generation Hancock extracorporeal pericardial valve was mainly caused by the poorly designed stenting, leading to wear and tear of the pericardial tissue. The valve was withdrawn from the market because of the extraordinary high failure rate. In our series 14 of the 90 exchanged aortic valves were investigated by means of light and electron microscopy. ${ }^{4}$ Degenerated valves (13/14) had cusp tears originating at the border zones of the pericardium and the stent material. Valve leaflets were thickened, and calcification was demonstrated in the vast majority of valves (13/14). Electron microscopy showed evidence of leukocyte infiltration of the collagen matrix with phagocytosis and, as other features, lipid, plasma protein, and calcium deposits. We hypothesized that both factors, premature calcification and increased mechanical stress, contributed to valve failure and that atherosclerosis might be involved in the degeneration of aortic bioprostheses, as previously demonstrated for the native aortic valve. $^{1}$

Dyslipidemia indicated by high total cholesterol $(>240$ $\mathrm{mg} / \mathrm{dL}$ ) levels was significantly associated with premature valve degeneration; the effect of triglyceride levels was still significant but minor. In elderly patients high cholesterol and triglyceride levels had no effect on the reoperation rate. However, the effect of total cholesterol as a risk factor decreases in the elderly, and atherosclerosis is more closely related to decreased levels of high-density lipoprotein cholesterol. ${ }^{5}$ Unfortunately, data on cholesterol subfractions were not available from our patients as a proof.
Interestingly, female sex is a risk factor for early degeneration of bioprostheses, which has been reported previously. ${ }^{2}$ With increasing age, the effect decreases, leading to the hypothesis that sex hormones might be involved in degenerative processes. However, in our study female sex was also associated with significantly higher preoperative levels of cholesterol and triglycerides.

Although this study is of limited size and retrospective in design, it is suggestive of the hypothesis that risk factors of atherosclerosis play a substantial role in the degeneration of aortic bioprosthetic valves. If this association is confirmed in other bioprostheses (eg, porcine valves or third-generation pericardial valves), lowering of serum lipids, smoking cessation, therapy for diabetes, and careful patient selection could be strategies to postpone degeneration. Younger patients could then possibly benefit from the advantages of bioprostheses.

\section{References}

1. Mohler ER 3rd. Are atherosclerotic processes involved in aortic-valve calcification? Lancet. 2000;356(9229):524-5.

2. Blackstone EH, Kirklin JW. Death and other time related events after valve replacement. Circulation. 1985;72:753-67.

3. Hammermeister K, Sethi GK, Henderson WG, et al. Outcomes 15 years after valve replacement with a mechanical versus a bioprosthetic valve: final report of the veterans affairs randomized trial. J Am Coll Cardiol. 2000;36:1152-8.

4. Vetter HO, Krupa W, Nerlich A, et al. New morphologic aspects of explanted Hancock extracorporeal pericardial bioprostheses. J Heart Valve Dis. 1994;3:335-43.

5. Corti MC, Guralnik JM, Salive ME, et al. HDL cholesterol predicts coronary heart disease mortality in older persons. JAMA. 1995;274:53944. 